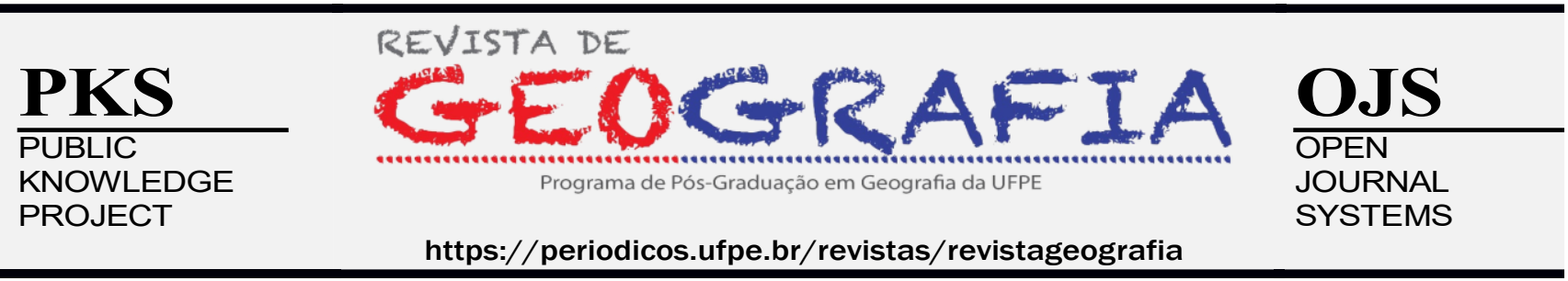

\title{
A EMERGÊNCIA DOS CONTACT CENTERS NO RIO GRANDE DO NORTE: UM PONTO NODAL NA REDE DE TELEATENDIMENTO BRASILEIRA
}

\author{
Aldeíze Bonifácio da Silva ${ }^{1}$ \\ ${ }^{1}$ Universidade Federal do Rio Grande do Norte (UFRN), E-mail:aldeizebs@hotmail.com, Orcid: http://orcid.org/0000- \\ 0002-5486-4889
}

Artigo recebido em 11/02/2021 e aceito em 04/10/2021

\section{RESUMO}

As empresas de contact centers são uma realidade recente no contexto brasileiro e configuram redes corporativas de localizações geográficas interconectadas entre si por ligações materiais e imateriais, sobretudo, fluxos informacionais, que se dispersam no território através de diversas outras "redes técnicas engendradas no bojo da expansão capitalista" (CORRÊA, 1997, p. 108). Perante o exposto, o objetivo do trabalho é compreender a dinâmica que perpassa a emergência das empresas de contact centers no Rio Grande do Norte enquanto um ponto nodal na rede de teleatendimento brasileira. Interesse que parte da constatação do crescimento significativo do número de empresas de teleatendimento no país e o aumento da participação relativa do setor na geração de emprego e de riquezas, sobretudo a partir de 2005. Para tanto, parte-se da pesquisa bibliográfica e documental, buscando dados sobre a origem e trajetória evolutiva dos contact centers no Brasil, no intuito de identificar a intencionalidade por trás da emergência destas empresas no Rio Grande do Norte. Os resultados obtidos demonstram a importância das políticas neoliberais e das redes infraestruturais na implantação e expansão do setor de teleatendimento brasileiro, determinantes no contexto das estratégias territoriais das empresas que consistem primordialmente na dispersão para a região Nordeste.

Palavras-chave: contact centers; redes infraestruturais; redes corporativas; Rio Grande do Norte.

\section{THE EMERGENCY OF CONTACT CENTERS IN RIO GRANDE DO NORTE: A NODAL POINT IN THE BRAZILIAN TELESERVICE NETWORK}

\begin{abstract}
Contact center companies are a recent reality in the Brazilian context and are configured in corporate networks of interconnected geographical locations by material and immaterial connections, especially information flows, which are dispersed in the territory through several other "technical networks engendered in the bulge of capitalist expansion" (CORREA, 1997, p. 108). The objective of this work is to understand the dynamics of emergence of contact center companies in Rio Grande do Norte as a nodal point in the Brazilian teleservice network. Interest that part of the significant growth in the number of teleservice companies in the country and
\end{abstract}


the increase in the relative participation of the sector in the generation of jobs and wealth, especially from 2005. To this end, we use the bibliographic and documentary research, seeking data on the origin and evolutionary trajectory of contact centers in Brazil, in order to identify the intentionality behind the emergence of these companies in Rio Grande do Norte. The results obtained demonstrate the importance of neoliberal policies and infrastructure networks in the implementation and expansion of the Brazilian teleservice sector, determinant in territorial strategies of companies which consist primarily in dispersion to the Northeast region.

Keywords: contact centers; infrastructure networks; corporate networks; Rio Grande do Norte.

\section{INTRODUÇÃO}

O termo rede remonta ao século XII. Sua concepção está inicialmente atrelada ao trabalho de artesãos ao entrelaçar fios. Posteriormente, o termo passa a fazer parte do âmbito médico no que concerne ao funcionamento do corpo humano. Somente "no século XIX passa a designar o tráfego, caminhos, estradas e ferrovias que atravessavam" os territórios (OLIVEIRA, 2014, p. 115).

Segundo Dias (2000, p. 144), o termo rede, pouco usual até a primeira metade do século XIX, aparece em obras dos discípulos do filósofo e economista francês Saint-Simon, que na linha de um socialismo planificador e tecnocrático defendeu a criação de um Estado organizado racionalmente por cientistas e industriais.

Ainda no que concerne à origem do termo, Guillerme (1986, p. 30) aponta que o termo também despontou, entre 1821 e 1828, para designar redes de fortificações e para qualificar a rede de distribuição de água de Paris. O estudo das redes abarcava então três eixos:

[O da] engenharia militar, [...] cujos oficiais estudavam em meados do século XVIII, o sistema de fortificações em todo o território, [o da] engenharia civil, [com os] engenheiros que trabalhavam no final do século XVIII e no início do século XIX com o abastecimento de água das grandes cidades, [e o da] medicina, especialmente a anatomia, que usa desde meados do século XVII o conceito de rede para definir a circulação sanguínea e o sistema nervoso. (GUILLERME, 1986, p. 30).

No âmbito da ciência geográfica os estudos sobre as redes constituem-se numa tradição que remonta o início do século XX, com Walter Christaller em 1933 (CORRÊA, 1997a, p. 208), e parte da necessidade de dimensionamento técnico e regulatório nos processos de normatização de diversas estruturas econômicas.

Além de Christaller, diversos geógrafos se debruçaram sobre a temática das redes, dentre os quais, Pierre Monbeig, geógrafo francês que em 1952 estudou o papel das redes ferroviárias sobre a 
organização espacial. Nesse contexto, com base no avanço das inovações técnicas, produziu-se desde a década de 1970 uma vasta literatura sobre o papel das redes na organização territorial.

Contemporaneamente a questão das redes perpassa uma abordagem focada nas relações que se estabelecem dentro do território, na organização e distribuição espacial dos fenômenos, ou seja, envolvem a urbanização, a divisão territorial do trabalho e a diferenciação crescente das cidades. Em suma, abarca o âmbito econômico e de transformação dos territórios, que dão ênfase à técnica enquanto infraestrutura e possibilidade de ação (DIAS, 2000, p. 149).

Na geografia alguns autores se ocuparam com a formulação de tipologias para as redes. Corrêa (1997a, p. 107), foi um que preocupado em reforçar a geograficidade das redes, elaborou uma detalhada tipologia considerando a existência das dimensões organizacional, temporal e espacial na sua constituição. Para o referido autor, as redes são “um conjunto de localizações geográficas interconectadas entre si por um certo número de ligações".

Enquanto um construto social, as redes são elaboradas a partir de relações que envolvem poder e cooperação (CORRÊA, 2012, p. 107). Nesse sentido, as redes são móveis e inacabadas, e como instrumentos do poder devem ser encaradas como estruturas reveladoras das ações de poder no território, visto que a rede "faz e desfaz as prisões do espaço tornado território" (RAFFESTIN, 1993, p. 185).

Para Santos (1999, p. 176) as redes são uma realidade técnica (material) e social. A materialidade caracteriza-se pela infraestrutura que possibilita a cooperação mútua de equipamentos. Por sua vez, a realidade social, constituída pelas relações sociais e pelas ações políticas, caracterizase pelas mensagens e valores que constroem e reconstroem constantemente as redes.

Perante a existência de inúmeras e distintas redes sobre a superfície terrestre, diversas tipologias de redes foram desenvolvidas, e convergem, de certo modo, para dois grandes conjuntos: o das redes técnicas ou infraestruturais e o das redes de serviços ou organizacionais (PEREIRA, 2009, p. 123). Os dois conjuntos de redes, técnicas e de serviços, se "condicionam reciprocamente e dialeticamente, visto que as redes de serviços são constituídas a partir das redes materiais e de pontos ativados no território", e as redes técnicas "não teriam razão para existir se não fossem animadas pelas atividades que são organizadas entre diferentes localizações no território a partir de suas estruturas" (PEREIRA e KAHIL, 2006, p. 218). 
Partindo da premissa do espaço geográfico como um conjunto indissociável de sistemas de objetos e sistemas de ações, a rede pode ser compreendida como um sistema verticalmente orientado pela e para a ação/intenção de determinados agentes, para a coordenação do trabalho que flui entre pontos específicos no território (SANTOS, 1999, p. 225). Portanto, “as redes não são apenas materialidade, mas também estratégias políticas de organização dos diferentes agentes e pontos no território, que são mobilizados e coordenados por outros agentes na intenção de desenvolver objetivos específicos" (PEREIRA e KAHIL, 2006, p. 220).

Assim, cada momento histórico é formado por um conjunto singular de conteúdo técnico, normativo e ações, no qual "as técnicas permitem uma forma de trabalhar e dividir o trabalho, enquanto a política autoriza ou prescreve essas possibilidades técnicas" (SILVEIRA, 2008, p. 5). Nesse sentido, “as redes são, ao mesmo tempo, concentradoras e dispersoras, condutoras de forças centrípetas e centrífugas" (SANTOS, 1999, p. 188).

No que tange às redes, encontramos as redes corporativas, que são redes geográficas, pontos distintos que se interconectam e se articulam através da interação entre sistemas de objetos e sistemas de ações (SANTOS, 1999, p. 38), simultaneamente sociais e espaciais (CORRÊA, 2012, p. 199). Redes que se materializam a partir de investimentos, pensados e programados segundo uma lógica global, que resulta na criação ou reestruturação de inúmeras outras redes, que dependem de todo um aparato técnico-informacional para operarem, usufruindo de toda a infraestrutura existente em um dado território que possibilite a sua interação com outros pontos do espaço, ou seja, atuam com base nas vantagens oferecidas por uma dada rede urbana.

Nesse contexto, as empresas de contact centers, que conformam o setor de teleatendimento, constituem redes materiais e imateriais que perpassam e se conectam aos mais distintos territórios, em decorrência do uso intensivo de tecnologias da informação. Desse modo, o processo produtivo destas empresas se materializa no território a partir de múltiplas escalas, em geral, conectando e integrando o território nacional a partir de intencionalidades externas ao âmbito local onde se instalam. $\mathrm{O}$ que resulta em novas interações espaciais.

Perante o exposto, o objetivo da pesquisa é compreender a dinâmica que perpassa a emergência das empresas de teleatendimento ${ }^{1}$ no Rio Grande do Norte enquanto um ponto nodal na rede de teleatendimento brasileira, em especial no que concerne às motivações e intencionalidades que resultam na crescente, porém, ainda insipiente, implantação de contact centers no estado. A pesquisa, que faz parte das reflexões que permeiam a dissertação de mestrado, emerge da constatação 
da expansão do setor de teleatendimento brasileiro, que tem sua gênese na privatização do setor de telecomunicações ${ }^{2}$ na década de 1990, com o crescente aumento do número de empresas e população ocupada na atividade.

Para compreendermos a divisão territorial do trabalho no setor de teleatendimento utilizamos como recurso metodológico à pesquisa bibliográfica e documental. A pesquisa bibliográfica ocorreu em dois momentos. O primeiro momento foi marcado pela busca de um referencial teórico que embasasse uma discussão sobre contact centers. Nesse sentido, refletimos sobre a ideia de redes, e a partir de autores como Roberto Lobato Corrêa, Milton Santos e Leila Christina Dias, foi possível trabalhar sob uma perspectiva geográfica o nosso temário de estudo.

Posteriormente, buscamos materiais já publicados (dissertações e teses) que nos ajudasse quanto à origem e trajetória evolutiva dos contact centers no Brasil. Fase que foi aliada a pesquisa documental, onde acessamos bancos de dados como o do Instituto Brasileiro de Geografia e Estatística (IBGE) - Cadastro de Central de Empresas (CEMPRE)-, do Ministério do Trabalho e Emprego (MTE) - Cadastro Geral de Empregados e Desempregados (CAGED) e Relação Anual de Informações Sociais (RAIS) -, da Associação Brasileira de Telesserviços (ABT), e sites relacionados à indústria de serviços de contact centers, assim como, sites das empresas do setor.

Assim, o trabalho estrutura-se em dois grandes tópicos. O primeiro tópico versa sobre a origem e trajetória das empresas de contact centers, com ênfase no contexto brasileiro, e o segundo traz uma discussão mais focada no Rio Grande do Norte enquanto um ponto nodal na lógica da rede corporativa do setor de teleatendimento no país. Após a discussão mencionada pontuamos algumas questões que consideramos pertinentes dentro do temário abordado nas considerações finais.

\section{A EXPANSÃO DAS EMPRESAS DE CONTACT CENTERS NO CONTEXTO BRASILEIRO}

Os contact centers possuem gênese nas antigas centrais telefônicas da década de 1950 . Nascem nos Estados Unidos (EUA) pela confluência das técnicas de marketing, vendas e telecomunicações e se expandem pelo mundo. A atividade, que consiste em uma forma de

$\overline{1}$ Denominação adotada pelo Instituto Brasileiro de Geografia e Estatística (IBGE), utilizada no presente trabalho como sinônimo de call centers e contact centers como são conhecidos usualmente.

2 Com a privatização do sistema Telebrás em 1988 o mercado de telefonia se abre para a concorrência privada e o acesso às linhas de telefone fixo e móvel são ampliadas. 
racionalização das operações de contato com agentes externos, chega ao Brasil na década de 1970. Todavia, a tomada de consciência da importância do setor de teleatendimento como suporte às demais atividades econômicas no país só ocorre em 1980, resultando na criação da Associação Brasileira de Telesserviços (ABT) por executivos e empresários do setor.

\footnotetext{
Em linhas gerais, o mercado de teleatendimento brasileiro segue o panorama mundial. Consiste basicamente em empresas terceirizadas, com um campo de atuação bastante amplo e diversificado, no qual temos desde os serviços clássicos de venda de produtos (telemarketing), informação e reclamação (SAC), pesquisa de mercado, cobrança de inadimplentes, atualização de cadastros, resolução de demandas de clientes, a gestão dos negócios de outras empresas-clientes. (SILVA, 2018, p. 22).
}

Segundo Silva (2018, p. 22-23), entre os principais contratantes dos contact centers estão os bancos, as lojas de varejo, as empresas de telecomunicações, as seguradoras, as administradoras de cartões de crédito, de planos de saúde, entidades previdenciárias, indústrias de alimentos, redes hoteleiras, agências de turismo, companhias aéreas, universidades, editoras, entre outras instituições. Cabe frisar que a demanda por esse tipo de serviço se mantém independentemente do cenário econômico, quando há aquecimento da economia, os serviços mais procurados são os de vendas, quando há recessão, os serviços mais procurados são os de cobrança.

Apesar de existirem no país desde a década de 1970, as empresas de contact centers somente se difundem pelo território brasileiro no contexto neoliberal com a privatização do setor de telecomunicações. Em linhas gerais, as políticas neoliberais, instauradas na década de 1990, representaram para o setor nacional mais do que a entrada de empresas e capital estrangeiro no país, pois possibilitaram a abertura de um mercado no qual as detentoras do controle do sistema telefônico brasileiro criaram empresas especializadas em serviços de teleatendimento com o objetivo reduzir custos de produção, ao mesmo tempo em que impulsionaram o surgimento de um "novo" segmento especializado em dar suporte às empresas de contact centers (ALMEIDA, 2013, p. 13).

Como a atividade de teleatendimento é marcada pelo uso intensivo das Tecnologias da Informação e Comunicação (TIC's), os primeiros contact centers a serem implantados no país se localizaram em São Paulo, estado com maior densidade técnica-informacional no período. Posteriormente, seguindo a própria trajetória econômica brasileira, outros estados do Sudeste passam a desenvolver a atividade em seus territórios, com destaque para os estados de Minas Gerais e Rio de Janeiro, respectivamente (IBGE, 2019). 
Ainda no que diz respeito à distribuição geográfica das empresas de teleatendimento no território brasileiro, Almeida (2013, p. 56) ressalta que a grande concentração de empresas de contact centers no estado de São Paulo reflete o poder de comando da capital paulista dentro do contexto nacional, visto as inúmeras redes (técnicas e de serviços) que perpassam seu território.

Desde o início da atividade de teleatendimento no país tivemos a participação de capital internacional no setor, em associação ou não, com o capital nacional, e também empresas nacionais coexistindo e concorrendo com empresas estrangeiras. O capital estrangeiro conecta o território nacional aos seus países de origem de duas formas: investindo em empresas brasileiras ou mantendo filiais das suas empresas de teleatendimento no país.

Dentro do contexto de participação do capital estrangeiro no mercado de teleatendimento brasileiro, apresentamos na Tabela 1 as 20 principais empresas terceirizadas do ramo que atuavam no país em 2017, e apesar dos dados estarem defasados, podemos perceber que no período ainda é marcante a presença de capital estrangeiro no setor, a saber: capital de origem americano, francês, italiano, português e espanhol.

Tabela 1 - Ranking das principais empresas de contact centers no Brasil (2017)

\begin{tabular}{|c|c|c|c|c|c|c|c|}
\hline & Empresa & $\begin{array}{l}\text { Faturamento } \\
\text { (R\$) em } 2017\end{array}$ & PA's* & Operador** & $\begin{array}{c}\begin{array}{c}\text { Funcionários } \\
\text { Total }\end{array} \\
\end{array}$ & Site*** & $\begin{array}{l}\text { Origem } \\
\text { do capital }\end{array}$ \\
\hline $1^{\circ}$ & Atento & 3.194 .259 .641 & 52.139 & $\mathrm{ND} * *$ & 78.803 & 35 & Espanha \\
\hline $2^{o}$ & Liq & 1.887 .269 .946 & 22.419 & 38.890 & 45.764 & 17 & Brasil \\
\hline $3^{\circ}$ & Almaviva & 1.002 .878 .000 & 17.000 & 26.723 & 29.769 & 10 & Itália \\
\hline $4^{\circ}$ & Algar Tech & 988.030 .427 & 5.000 & 6.364 & 12.148 & 4 & ND**** \\
\hline $5^{\circ}$ & $\mathrm{AeC}$ & 816.003 .000 & 14.148 & 18.896 & 22.403 & 14 & Brasil \\
\hline $6^{\circ}$ & Neobpo & 604.401 .000 & 16.000 & 12.485 & 15.634 & 11 & Inglaterra \\
\hline $7^{\circ}$ & Flex & 580.204 .000 & 8.000 & 10.212 & 12.772 & 14 & Brasil \\
\hline $8^{\circ}$ & Vikstar & 487.930 .942 & 5.816 & 11.283 & 18.521 & 9 & Brasil \\
\hline $9^{\circ}$ & Paschoalotto & 381.884 .352 & 7.200 & 5.574 & 6.522 & 6 & Brasil \\
\hline $10^{\circ}$ & Tel & 340.000 .000 & 7.100 & 13.000 & 15.000 & 9 & Brasil \\
\hline $11^{\circ}$ & Uranet & 294.896 .720 & 3.254 & 3.532 & 4.892 & 5 & $\mathrm{ND} * * * *$ \\
\hline $12^{\circ}$ & $C S U$ & 272.772 .727 & 2.082 & 3.935 & 5.208 & 4 & Brasil \\
\hline $13^{\circ}$ & Sitel & 128.350 .000 & 2.411 & 2.095 & 2.624 & 3 & Eua \\
\hline $14^{\circ}$ & Elo & 95.000 .000 & 1.537 & 1.948 & 2.352 & 3 & Brasil \\
\hline $15^{\circ}$ & Voxline & 80.000 .000 & 1.110 & 1.700 & 1.880 & 2 & Brasil \\
\hline $16^{\circ}$ & Pluris Mídia & 66.934 .795 & 980 & 915 & 1.312 & 2 & 68.301 \\
\hline $17^{\circ}$ & Concentrix & $\mathrm{ND}^{* * * *}$ & 2.568 & 1.608 & 1.907 & 5 & $\mathrm{ND} * * * *$ \\
\hline $18^{\circ}$ & Kainos & $\mathrm{ND} * * * *$ & 1.800 & 1.400 & 1.550 & 4 & $\mathrm{ND} * * * *$ \\
\hline $19^{\circ}$ & Teleperformance & $\mathrm{ND} * * * *$ & 11.000 & 15.333 & 17.848 & 10 & França \\
\hline $20^{\circ}$ & Dedic & $\mathrm{ND} * * * *$ & 8.178 & 19.096 & $\mathrm{ND}^{* * * *}$ & 9 & Portugal \\
\hline & Total & 11.220.815.550 & 189.742 & 191.299 & 291.929 & 176 & ----- \\
\hline
\end{tabular}

Fonte: Centro de Inteligência Padrão (CIP), 2018.

Notas:

* Pontos de atendimento, ou seja, postos de trabalho.

** Designação dos profissionais de teleatendimento.

*** Jargão do setor para unidades operacionais.

**** Não divulgado pelas empresas. 
Atualmente algumas destas empresas passaram por fusões nas quais grandes corporações do setor se unificaram, passando a ter um capital misto, e em outros casos ocorreram aquisições de empresas de pequeno porte já consolidadas no mercado de teleatendimento brasileiro.

Ainda com relação aos dados apresentados na Tabela 1, constatamos que apenas 20 das principais empresas terceirizadas que atuavam no país em 2017 foram responsáveis pela geração de mais de 291.929 postos de trabalho e um faturamento de mais de $\mathrm{R} \$ 11,2$ bilhões no referido ano.

Destarte, o que caracteriza o período atual da "indústria" de serviços de contact centers é a dimensão do seu mercado, que vem crescendo, sobretudo, a partir dos anos 2000, em decorrência de normatizações que culminaram com a criação do código de defesa do consumidor e a terceirização do setor de teleatendimento.

A obrigatoriedade legal das empresas manterem um canal de comunicação direto com o consumidor fez com que inúmeras empresas fossem criadas para dar conta de tal demanda. Posteriormente, com a implantação da terceirização no setor de teleatendimento, as empresas passaram a contratar empresas para realizar o serviço ao invés de manter um setor de teleatendimento próprio, reduzindo os custos de produção.

Quando analisamos o setor de teleatendimento brasileiro, podemos ter um vislumbre parcial da dimensão do mercado de contact centers nacional a partir da análise de algumas variáveis, a saber: o número de empresas operando no país, o número total de pessoal ocupado no setor, o número de postos de trabalho físico existentes, que expressam a capacidade de expansão do setor, e seu faturamento.

Nesse sentido, apresentamos na Tabela 2 a evolução do mercado brasileiro de contact centers a partir de dados referentes ao crescimento do número de empresas e do quantitativo de pessoal ocupado no setor, no período entre 1999 e 2017. Os dados apresentados foram obtidos através do Cadastro Central de Empresas do Instituto Brasileiro de Geografia e Estatística e no Portal Call Center, site direcionado às empresas e aos profissionais do setor de teleatendimento. 
Tabela 2 - Evolução do mercado de contact centers brasileiro (1999-2017)

\begin{tabular}{|c|c|c|c|c|}
\hline \multirow[t]{2}{*}{ Período/ano } & \multirow{2}{*}{$\begin{array}{c}\text { Número } \\
\text { de } \\
\text { Empresas* }\end{array}$} & \multirow{2}{*}{$\begin{array}{c}\text { PA's** }^{* *} \\
\text { Quantidade }\end{array}$} & \multicolumn{2}{|c|}{$\begin{array}{c}\text { Trabalhadores no setor de } \\
\text { teleatendimento }\end{array}$} \\
\hline & & & Operadores*** & Total de funcionários \\
\hline 1999 & $\mathrm{DNE}^{* * * *}$ & 5.083 & 1.374 & 1.388 \\
\hline 2000 & $\mathrm{DNE}^{* * * *}$ & 14.450 & 3.058 & 3.068 \\
\hline 2001 & $\mathrm{DNE}^{* * * *}$ & 24.925 & 11.770 & 11.780 \\
\hline 2002 & $\mathrm{DNE}^{* * * *}$ & 35.066 & 23.712 & 29.120 \\
\hline 2003 & $\mathrm{DNE}^{* * * *}$ & 46.754 & 44.128 & 56.400 \\
\hline 2004 & $\mathrm{DNE}^{* * * *}$ & 92.255 & 156.554 & 180.695 \\
\hline 2005 & $\mathrm{DNE}^{* * * *}$ & 107.715 & 195.743 & 237.690 \\
\hline 2006 & 1.521 & 125.072 & 221.248 & 269.380 \\
\hline 2007 & 1.781 & 152.329 & 264.026 & 318.829 \\
\hline 2008 & 2.171 & 168.296 & 285.485 & 337.987 \\
\hline 2009 & 2.359 & 175.932 & 288.716 & 347.161 \\
\hline 2010 & 2.547 & 196.967 & 316.018 & 388.265 \\
\hline 2011 & 2.768 & 226.620 & 344.965 & 427.302 \\
\hline 2012 & 3.120 & 219.310 & 327.947 & 407.736 \\
\hline 2013 & 3.264 & 229.740 & 367.720 & 449.221 \\
\hline 2014 & 3.151 & 255.154 & 415.971 & 498.326 \\
\hline 2015 & 3.067 & 267.937 & 442.214 & 528.550 \\
\hline 2016 & 2.947 & 267.718 & 441.637 & 527.288 \\
\hline 2017 & 2.925 & 265.276 & 439.212 & 523.352 \\
\hline
\end{tabular}

Fonte: Portal Call Center ${ }^{3}, 2018$. Disponível em: http://callcenter.inf.br. Acesso em: ago. 2019.

Nota:

* Fonte dos dados: Cadastro Central de Empresas - IBGE, 2019.

** Pontos de atendimento, ou seja, postos de trabalho.

*** Designação dos profissionais de teleatendimento.

**** Dados não encontrados.

No que tange os dados apresentados na Tabela 2, observa-se que no período de 2006 a 2017 (intervalo temporal do qual obtivemos dados referentes ao quantitativo de empresas de contact centers no país), o número de empresas de teleatendimento apresentou um crescimento significativo.

Em 2006 existiam 1.521 empresas operando no território nacional, enquanto que em 2017 existiam 2.925 empresas no país. O número de empresas de teleatendimento quase duplicou. O

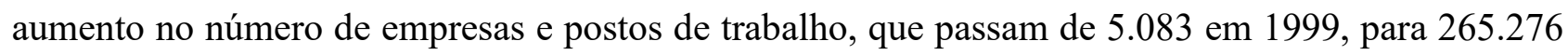
em 2017, refletem o aumento do contingente de mão de obra empregado na atividade, que em 2017 chegou a 523.353 indivíduos.

3 Portal eletrônico direcionado às empresas e aos profissionais do setor de teleatendimento. Iniciativa do Grupo Padrão, site que funciona como canal de comunicação dos contact centers da América Latina, com conteúdo nacional e internacional sobre gestão, tecnologia, regulamentação, indicadores, recursos humanos, faturamento, entre outros. 
Em suma, o mercado de contact center brasileiro apresentou em 2017, em termos quantitativos, um efetivo de 2.925 empresas, 523.352 pessoas ocupadas no setor, e um faturamento de aproximadamente $\mathrm{R} \$ 46,1$ bilhões (E-CONSULTING CORP $\left.{ }^{4}, 2017\right)$.

Ainda no que tange a apreensão de um panorama do setor de teleatendimento brasileiro, dados, mesmo que parciais ${ }^{5}$, apresentados na Relação Anual de Informações Sociais (RAIS) ${ }^{6}$, e sintetizados no Gráfico 1, demonstram que apesar do quantitativo de empresas e do pessoal ocupado no país sofrer oscilações durante o período de 2006 a 2019, e o auge do setor de teleatendimento ter ocorrido em 2014, ele continua em expansão.

Gráfico 1- Evolução do número de empresas de teleatendimento no país e regiões brasileiras (2006-2019)

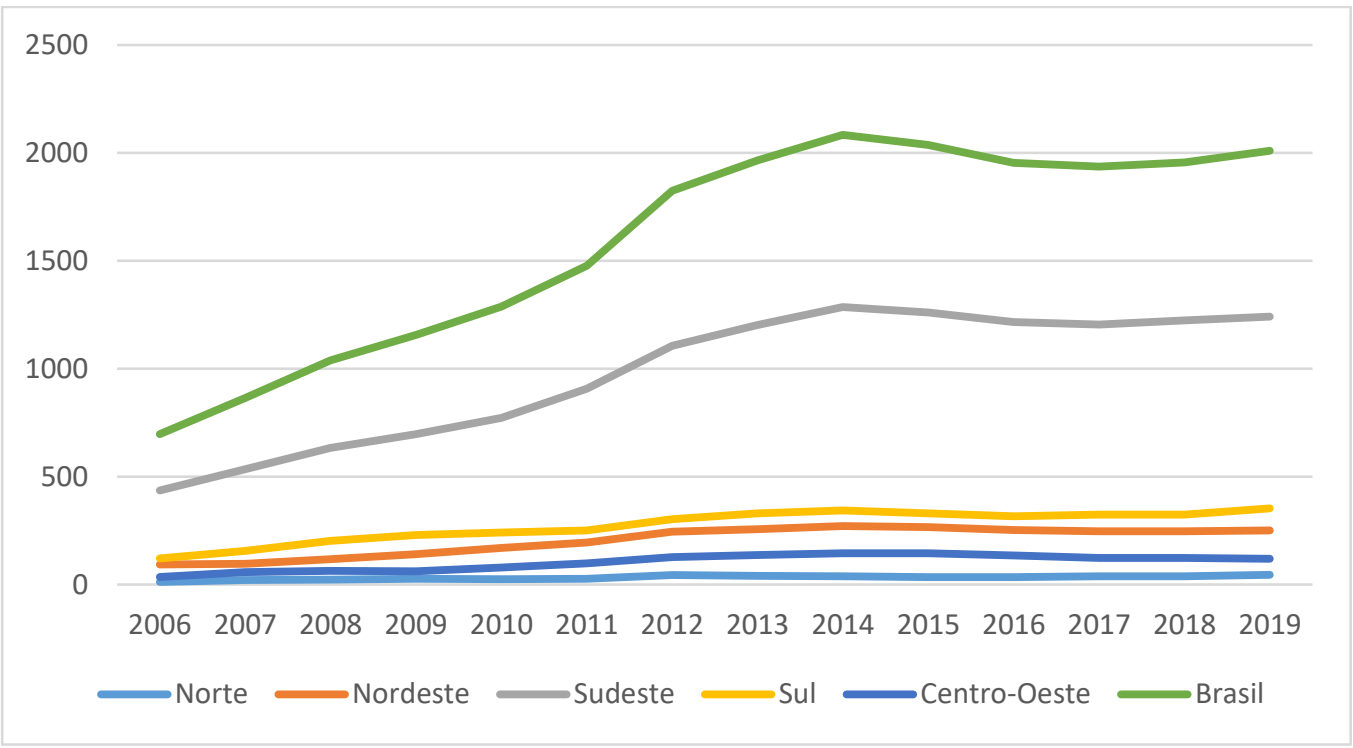

Fonte: RAIS/MTE, 2019.

Podemos constatar no Gráfico 1 que todas as regiões brasileiras apresentaram um aumento no número de empresas de contact centers em suas regiões. Todavia, a região Norte foi a que apresentou um menor crescimento no número de empresas de teleatendimento quando comparada as

4 Empresa de consultoria, especializada em desenvolvimento e implementação de serviços e pesquisa para empresas de contact centers.

5 Dados parciais por não contemplarem todas as instituições que exercem a atividade de teleatendimento no país, e sim, aquelas registradas exclusivamente na atividade de telesserviços.

6 Relatório de informações socioeconômicas solicitado pelo Ministério do Trabalho e Emprego (MTE) brasileiro às pessoas jurídicas e outros empregadores anualmente, instituído pelo Decreto nº 76.900 de 23 de dezembro de 1975 . 
outras regiões brasileiras, não apresentando números significativos no que tange ao efetivo de mão de obra empregada no setor, como podemos observar no Gráfico 2, que retrata a evolução do pessoal ocupado no setor de teleatendimento no período de 2006 a 2019.

Gráfico 2 - Evolução do pessoal ocupado na atividade de teleatendimento no país e regiões brasileiras (2006-2019)

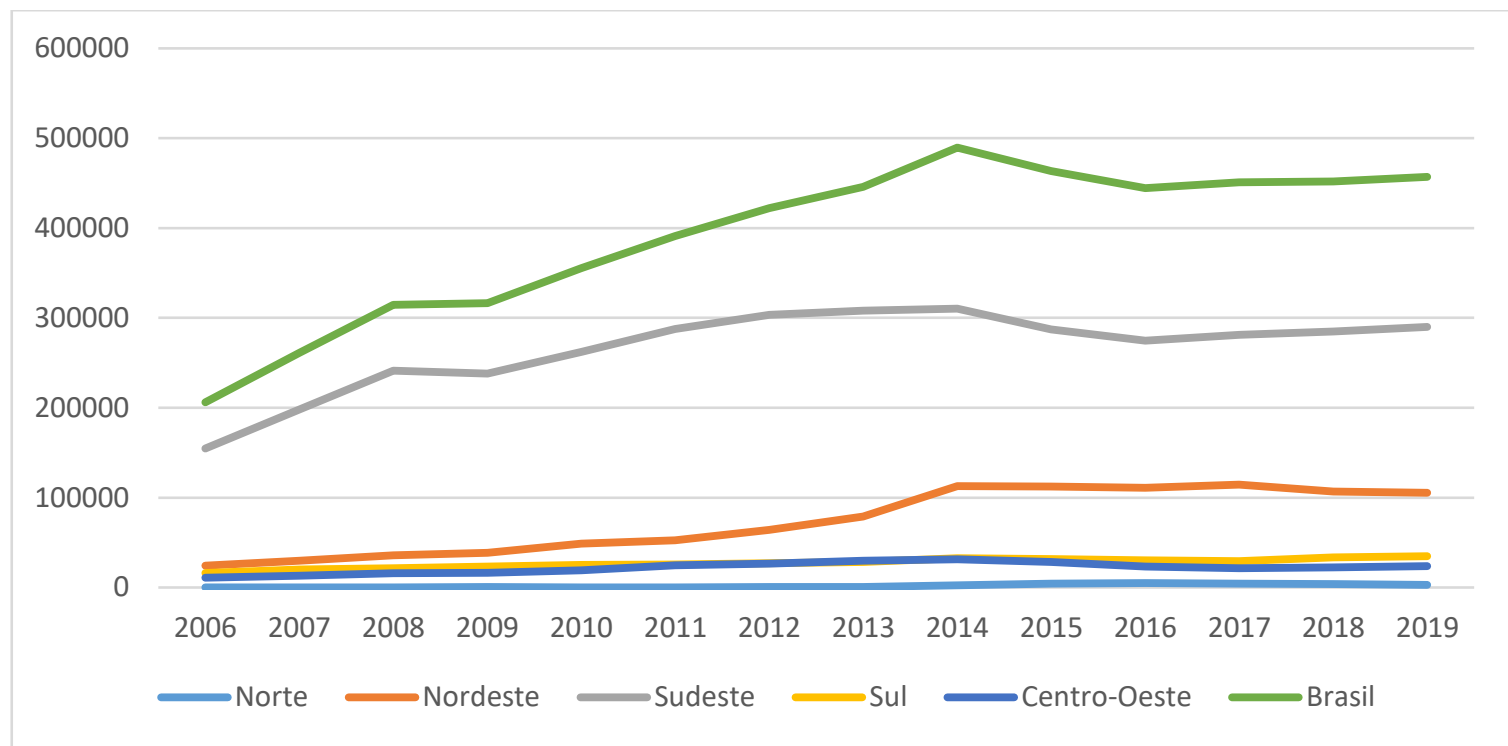

Fonte: RAIS/MTE, 2019.

Com base nos gráficos apresentados, podemos inferir que apesar da região Nordeste ainda apresentar um pequeno número de empresas e um baixo quantitativo de pessoal ocupado na atividade em comparação às regiões Sul, Sudeste e Centro-Oeste, a região passa a partir de 2012 a apresentar números mais expressivos que refletem mudanças nas estratégias territoriais das empresas do setor, tendo em vista que os altos custos relativos à produção nas grandes metrópoles e em outras cidades mais bem servidas de equipamentos e tecnologia, como os decorrentes ao aluguel de imóveis, salários, transporte e alimentação, contribuíram para a dispersão de unidades operacionais destas empresas para localidades que lhe garantam melhores vantagens competitivas.

Segundo dados levantados por Almeida (2013, p. 121) no Cadastro Geral de Emprego e Desemprego (CAGED) referentes ao período de 2011, o salário médio de um operador em São Paulo era de $\mathrm{R} \$ 849,72$, enquanto que em Caruaru, no agreste pernambucano, era de apenas $\mathrm{R} \$ 581,27$, situação que traduz uma das variáveis analisadas por uma empresa ao escolher um território em 
detrimento de outro para operar, e exemplifica a situação do Nordeste no contexto da dispersão do setor para outras regiões brasileiras.

Almeida (2013, p. 187) ressalta que além dos incentivos fiscais e dos benefícios territoriais (terrenos e infraestrutura) oferecidos pelos municípios e estados, na "guerra dos lugares" (SANTOS, 1999, p. 181) em busca de novos investimentos, a menor concorrência com os demais setores empregatícios, uma mão de obra barata e abundante, mas também, "comprometida" com a empresa, ou seja, que tenham poucas opções de emprego, para que assim se submetam aos sistemas de produção vigentes nos contact centers, são fatores de relevância dentro do panorama de estratégias territoriais de dispersão das unidades operacionais das empresas, levando estas empresas a considerar a região Nordeste em suas estratégias de aumento de lucratividade.

Perante o exposto, a expansão do setor de teleatendimento brasileiro caracteriza-se pelo fenômeno de dispersão espacial de unidades operacionais de filiais de empresas que atuam originalmente na região Sudeste, sobretudo, oriundas de São Paulo, que possui em seu território quase $50 \%$ das sedes das grandes empresas de teleatendimento (ALMEIDA, 2013, p. 120), em direção à região Nordeste. Nesse contexto, entre as principais localidades escolhidas por estas empresas para se instalarem estão os estados do Ceará, Bahia, Pernambuco e Rio Grande do Norte, respectivamente, como podemos observar na figura 1 , que retrata a dinâmica do setor de teleatendimento brasileiro. 
Figura 1 - Panorama síntese da dinâmica do setor de teleatendimento brasileiro (2019)

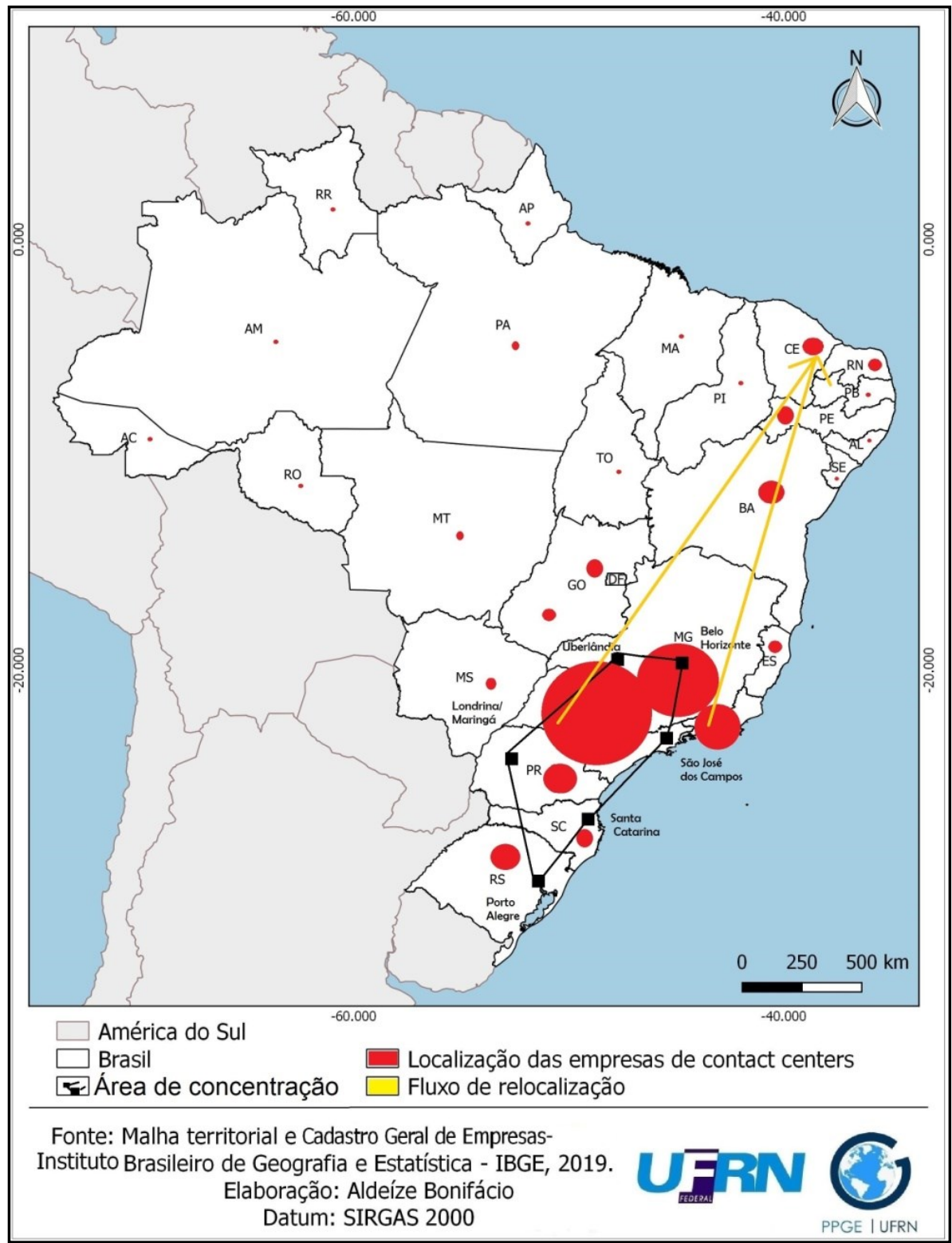

Fonte: Dados do Cadastro Central de Empresas - IBGE, 2019.

Na Figura 1, podemos observar a região concentrada de atuação do setor de teleatendimento que conforma um eixo Sul-Sudeste, com o predomínio de empresas do setor na região Sudeste, seguida pela região Sul, e o fluxo dispersivo destas empresas em direção a região Nordeste. Dinâmicas identificadas a partir da análise de dados do IBGE (2019) sobre a atividade de teleatendimento no período de 2007 a 2019. 


\section{O RIO GRANDE DO NORTE NA LÓGICA DA REDE CORPORATIVA DOS CONTACT CENTERS: UM PONTO NODAL NA REDE DE TELEATENDIMENTO BRASILEIRA}

Partindo da premissa que está em curso um fenômeno de dispersão espacial de unidades operacionais de contact centers da região Sudeste para a região Nordeste, e tendo em vista que as interações espaciais que perpassam a operacionalização da atividade de teleatendimento envolvem, sobretudo, o deslocamento de informação. É imprescindível para as empresas do setor, a existência de redes materiais e imateriais (internet banda larga, telefonia, etc.) a ligar as sedes das corporações a suas filiais espalhadas pelo território.

Para Toledo Júnior (2003, p.11), “a diferenciação regional decorrente da desigual distribuição das redes no território" brasileiro faz com que as empresas de contact centers se localizem em determinadas cidades ou eixos. Portanto, existe uma relação direta entre a localização das empresas de teleatendimento e os pontos de cobertura da rede de fibra ótica nacional, por exemplo.

Logo, a infraestrutura em telecomunicações como um todo, que perpassa os serviços de telefonia (fixa e móvel) e multimídia, é de suma importância para o setor de teleatendimento. O que faz com que a infraestrutura técnica seja uma das dimensões analisadas no processo de escolha locacional das empresas dentro do território nacional.

Nesse sentido, quando sobrepomos a infraestrutura em rede de fibra ótica brasileira e a localização das principais capitais que possuem sede de empresas do setor de teleatendimento, podemos observar, conforme expresso na Figura 2, que existe uma relação direta entre a rede de fibra ótica brasileira e a localização das sedes das empresas de contact centers no país. 
Figura 2 - Sobreposição da rede de fibra ótica brasileira e a localização das sedes das empresas de contact center (2013).

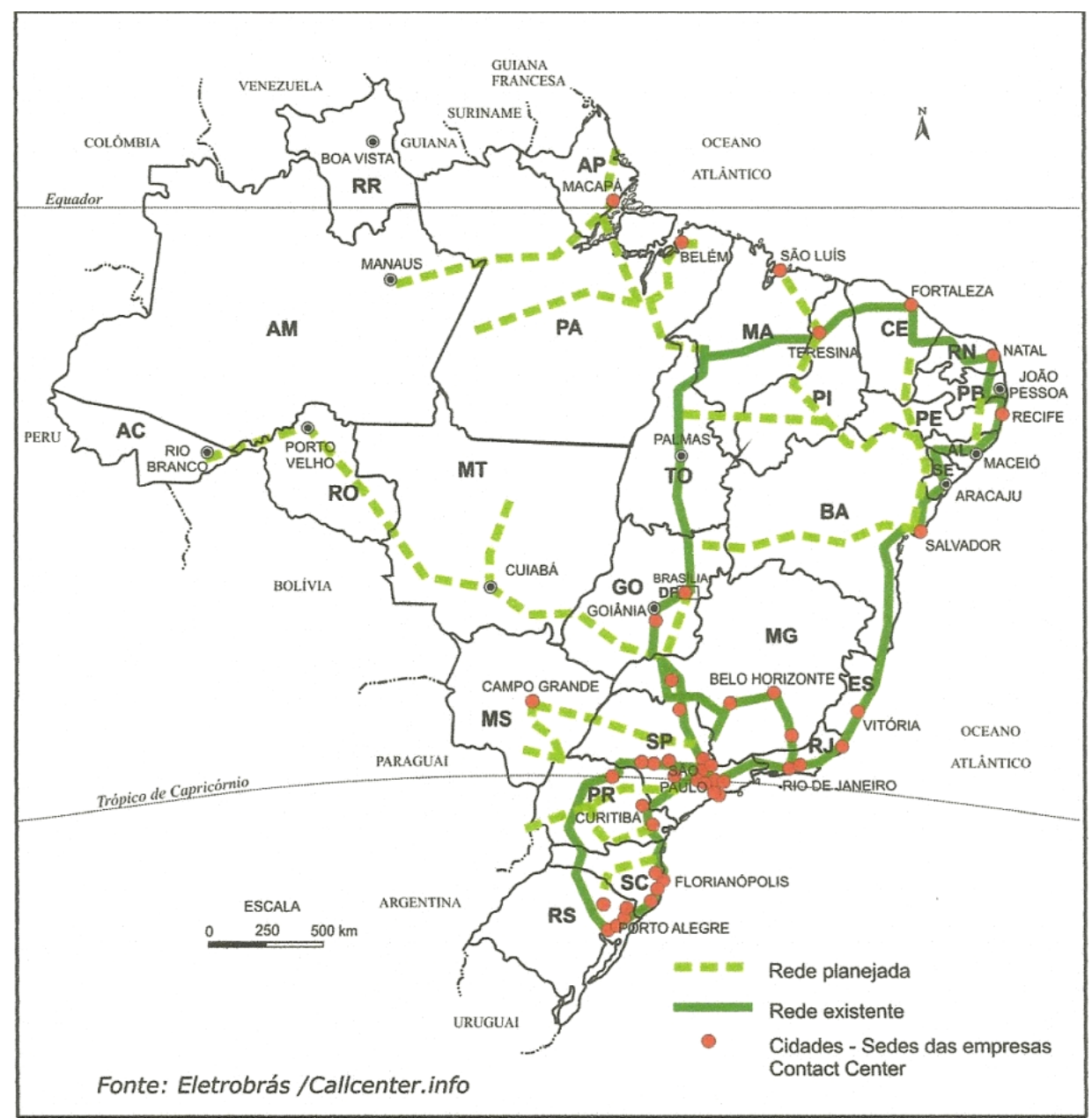

Fonte: Almeida, 2013.

Com base na Figura 2, constatamos que na divisão territorial do trabalho das empresas de contact centers ocorre a presença de forças centrípetas, com a manutenção das sedes, e assim, do poder, nas principais metrópoles brasileiras, e centrífugas, com a dispersão de unidades de operacionais para centros urbanos metropolitanos e não metropolitanos, sobretudo para a região Nordeste.

Desse modo, como reflexo do quadro síntese apresentado pela sobreposição da rede de fibra ótica com a rede corporativa de teleatendimento brasileira, temos o crescimento do número de empresas de contact centers instaladas, sobretudo, nas regiões metropolitanas de Salvador, Recife e Fortaleza, nas capitais Natal (RN), Mossoró (RN), João Pessoa (PB), Maceió (AL), Aracajú (SE), Teresina (PI) e São Luiz (MA), e em algumas cidades do interior como Caruaru (PE), Feira de Santana (BA) e Campina Grande (PB) (ALMEIDA, 2013, p. 24). 
No que tange ao setor de teleatendimento brasileiro, o Rio Grande do Norte ocupa atualmente a $4^{\circ}$ posição no ranking nordestino, apesar de apresentar números significativos no que concerne ao aumento de empresas de contact centers no seu território e ao quantitativo da sua população ocupada na atividade de teleatendimento, como podemos observar nos Gráficos 3 e 4, que tratam da evolução do setor de teleatendimento na região Nordeste.

No que concerne ao número de empresas instaladas em seu território, o estado perdeu posição nos últimos anos, mas vem mantendo um número constante de empresas desde 2012, apresentando uma crescente em termos de população ocupada no setor desde 2015. Cabe frisar que ambas as variáveis apresentavam uma crescente no que tange os referidos períodos.

Gráfico 3 - Evolução do número de empresas de teleatendimento por estados nordestinos (2006-2019)

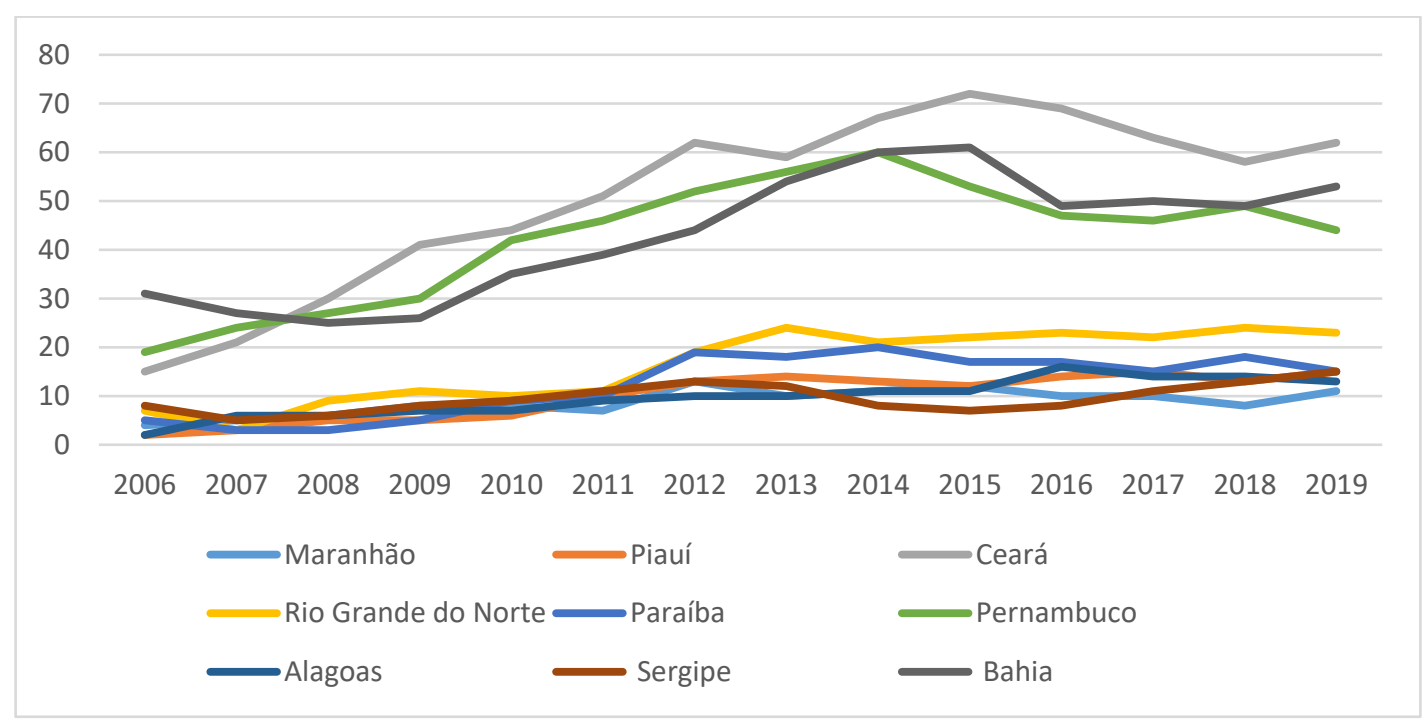

Fonte: RAIS/MTE, 2019. 
Gráfico 4 - Evolução do pessoal ocupado no setor de teleatendimento na região Nordeste (2006-2019)

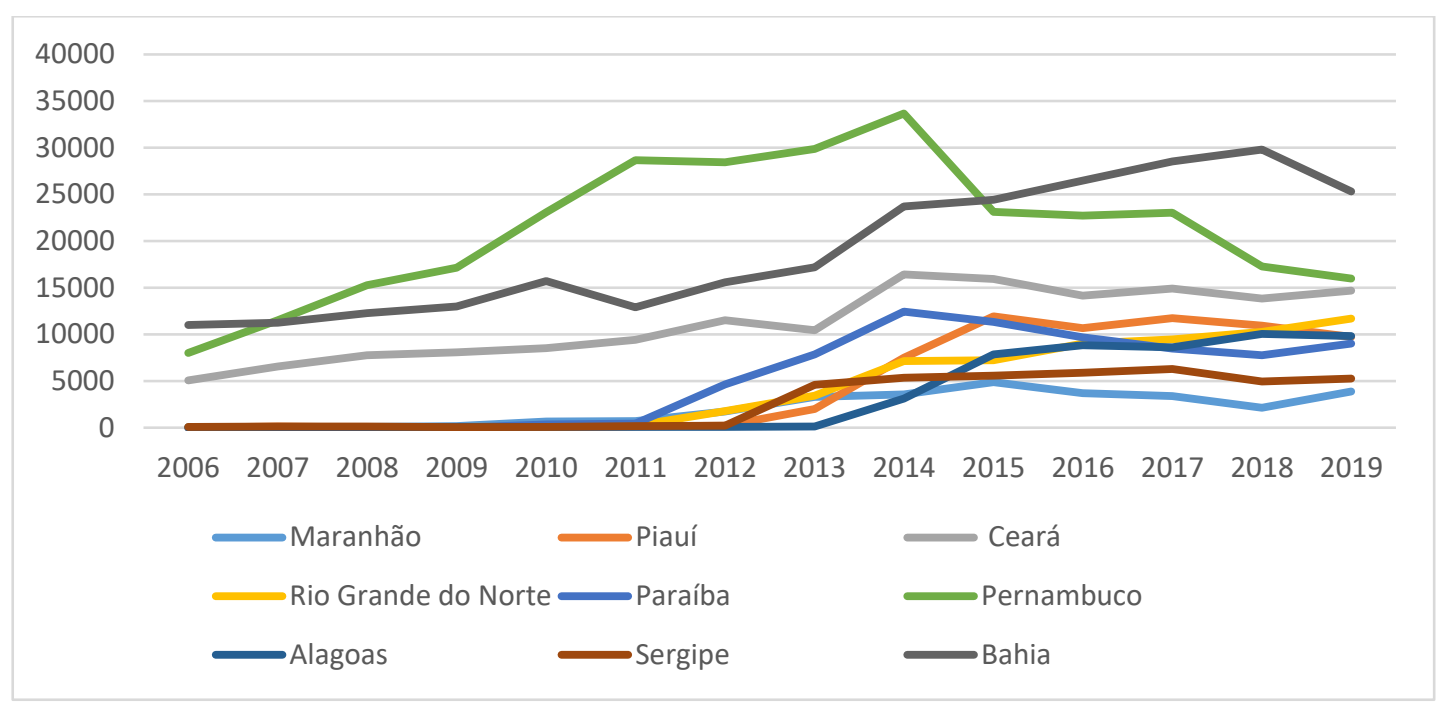

Fonte: RAIS/MTE, 2019.

Entre as principais empresas que atuam no contexto nacional e regional e possuem filiais no Rio Grande do Norte, temos: a $A e C$ que atua no Rio Grande do Norte, Pernambuco, Maranhão, Alagoas, São Paulo e Minas Gerais, e a francesa Teleperformance que atua no Rio Grande do Norte, São Paulo e em países como o Reino Unido, Albânia, Chile, Índia, Filipinas, China, Canadá, México, Colômbia, Noruega, Itália, Grécia, Portugal, Estados Unidos, Costa Rica, República Dominicana, Austrália, Holanda, Suriname, Egito, Rússia, Suécia, Alemanha e Polônia (SILVA, 2018, p. 54). No âmbito local temos: o Contact Center Riachuelo, que apesar de ter sua única unidade no Rio Grande do Norte, atende todo o país; a Global; a Cabo Telecom, entre outras empresas.

Em suma, as empresas de teleatendimento que atuam no Rio Grande do Norte se localizam em Mossoró, Natal, Parnamirim e São Gonçalo do Amarante. Escolha locacional fortemente atrelada às possibilidades decorrentes dos seus equipamentos urbanos, e das articulações que apresentam cada rede urbana (SILVA, 2018, p. 27).

Nessa perspectiva, os contact centers se articulam no território com suas empresas-clientes, para os quais prestam serviços terceirizados, mas também, com instituições de ensino superior privado, operadoras de planos de saúde e hospitais particulares. Atuando como modificadoras de fluxos e demandas dentro da cidade, do bairro, da rua onde se localizam, como por exemplo, no caso dos transportes públicos, com o aumento da demanda por uma determinada linha de ônibus em um horário específico, já que no geral, as empresas de contact centers possuem um grande contingente de funcionários, que irão confluir de diversos pontos da cidade para uma mesma localidade. 
A implantação de empresas de teleatendimento no Rio Grande do Norte só foi possível devido a melhoria nas condicionantes técnicas, sociais e normativas pelas quais o estado vem passando nas últimas décadas. A rede infraestrutural, sobretudo, as infovias e a telemática, tem um peso importante para o Rio Grande do Norte se tornar um ponto nodal na rede de teleatendimento brasileira. Assim como, a melhoria da rede de ensino potiguar e as decisões políticas direcionadas à conformação da atividade no estado.

No que tange a rede de fibra ótica potiguar, dados da Agência Nacional de Telecomunicações (ANATEL), referentes ao período de 2016 a 2019, demonstram que houve uma melhoria significativa nas condições infraestruturais do acesso a internet no estado. Em 2016, dentre os 167 municípios que compõem o estado, apenas 27,5\% possuíam cobertura de internet em fibra ótica, sendo que em 2019, esse percentual sobe para 55,1\% dos municípios potiguares, como exposto na Tabela 3.

Tabela 3 - Evolução dos municípios potiguares com cobertura de internet em fibra ótica (2016 a 2019)

\begin{tabular}{ccccc}
\hline Período de referência & $\mathbf{2 0 1 6}$ & $\mathbf{2 0 1 7}$ & $\mathbf{2 0 1 8}$ & $\mathbf{2 0 1 9}$ \\
\hline Número de municípios & 46 & 54 & 76 & 92 \\
Percentual (\%) & 27,5 & 32,3 & 45,6 & 55,1 \\
\hline \multicolumn{4}{c}{ Fonte: ANATEL, 2019.}
\end{tabular}

No que concerne a normatização do território potiguar, desde 2012 o Estado tem empreendido esforços no sentido de atrair a instalação de empresas de contact centers para seus municípios. Em linhas gerais, no Rio Grande do Norte os incentivos fiscais consistem em vantagens para as empresas parceiras do Programa Jovem Aprendiz ${ }^{7}$, que recebem como benefício, por exemplo, o pagamento de apenas 2\% de Fundo de Garantia do Tempo de Serviço (FGTS); a redução do Imposto Sobre Serviços (ISS) que incide sobre a prestação de serviços no município, de 5\% para $2 \%$ a alíquota mínima para empresas de ramo de contact centers com validade de 10 anos; e a isenção total de Imposto Predial e Territorial Urbano (IPTU) e do Imposto de Transmissão de Bens Imóveis Intervivos (ITBI), válidos também por 10 anos, mas renováveis por mais 10 anos, se as contrapartidas ${ }^{8}$ exigidas pelos municípios forem atendidas (SILVA, 2018).

Para exemplificarmos a participação do Rio Grande do Norte enquanto um ponto nodal na rede de teleatendimento brasileira, abordamos de forma superficial duas empresas do setor que

7 Benefícios regidos pela Lei Federal n $n^{\circ}$ 10.097, de 19 dezembro de 2000 (lei da aprendizagem). 
operam no estado, o Contact Center Teleperformance e o Contact Center Riachuelo, que se configuram e articulam-se de forma distintas.

A rede configurada pela empresa Teleperformance articula-se com inúmeras outras redes, dentre as quais, uma complexa rede formada pelo sistema bancário dos diversos países onde se localizam suas filiais, que somam um total de 24 países, e movimenta um capital que conflui para a França, onde está a sede da corporação.

A empresa é uma das líderes do mercado mundial e atua como prestadora de serviços terceirizados para clientes-empresas em nível global, o que envolve a estratégia locacional de implantação de suas filiais nos mais distintos países para prestar seus serviços em diversos idiomas, e para os mais diversos atores empresariais, desde bancos e financeiras de cartão de crédito, prestadoras de planos de saúde, hospitais, TV a cabo, telefonia, internet banda larga, etc. Nos segmentos de venda (telemarketing), pós-venda (Serviço de Atendimento ao Cliente - SAC, cobrança de inadimplentes, etc.) e atividades associadas ao fornecimento e a manutenção de infraestrutura tecnológica e gestão de negócios para empresas-clientes (Tecnologia da Informação - TI).

Em contrapartida, a rede constituída pelo Contact Center Riachuelo engloba todo o circuito de produção e distribuição que perpassa a dimensão do Grupo Guararapes no território nacional, ou seja, a sede da corporação, a matriz da loja Riachuelo e todas as inúmeras filiais materiais espalhadas pelos diversos estados brasileiros, assim como, a loja virtual (e-commerce) que atende a demanda de localidades onde não é possível encontrar a loja em sua estrutura física, a financeira do grupo que atua com o Visa e o Master Card e seus investidores estrangeiros, as fábricas, depósitos e distribuidoras dos produtos Riachuelo, os profissionais que trabalham com o design dos produtos, fornecedores da empresa (tecidos, peças importadas, acessórios, etc.), entre outros.

Na Figura 3, podemos observar a espacialização da rede do Contact Center Riachuelo, em um esquema simplificado no qual temos o contact center, no Rio Grande do Norte, a sede corporativa, em São Paulo, as lojas físicas, espalhadas por todas as 27 unidades federativas, e o e-commerce (loja virtual), que abrange todo o contexto nacional. Cabe frisar que para a melhor compreensão do esquema síntese desta rede, as diversas lojas existentes em um mesmo estado foram representadas por um símbolo único.

\footnotetext{
8 A manutenção da atividade de teleatendimento na região na qual a empresa foi implantada, a geração de empregos diretos, a contratação de pessoas do município na qual a empresa foi implantada em caráter prioritário e a progressividade exigida pela legislação vigente.
} 
Figura 3 - Rede espacial nacional da empresa Riachuelo S.A (2019)

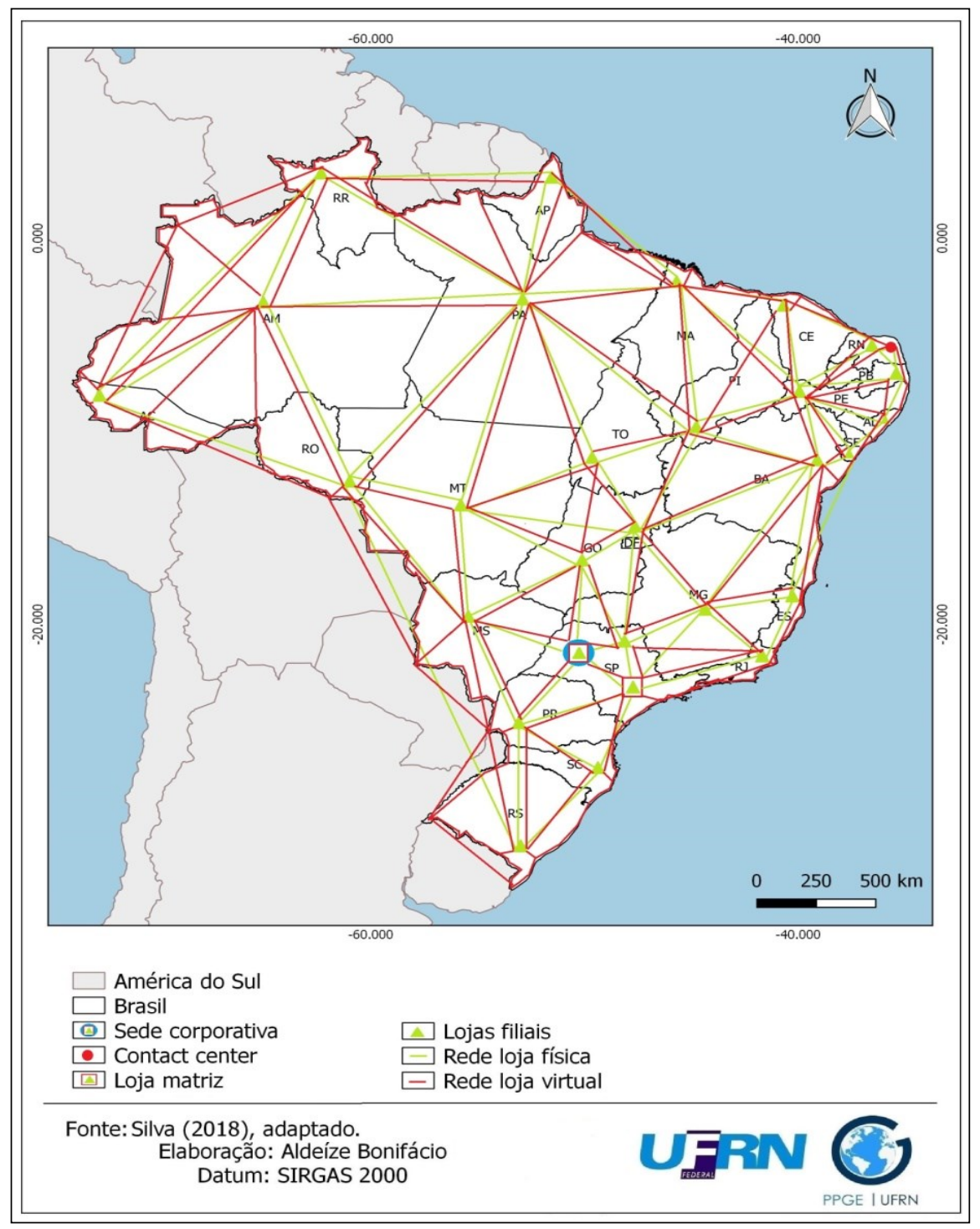

Fonte: adaptado de Silva, 2018.

A forma como o Rio Grande do Norte se insere nestas redes são distintas, visto o modo como estas empresas se estruturam operacionalmente. No contexto da Teleperformance, o Rio Grande do Norte se constitui em mais um ponto nodal no qual a empresa possui unidades operacionais, e por ser uma empresa terceirizada, a dialética entre Capital Privado-Estado no território é mais instável. A qualquer momento a empresa pode alocar a unidade instalada no estado para outra localidade que apresente condições mais vantajosas para potencializar a relação Empresa-Cartela de Cliente. Por sua vez, o Contact Center Riachuelo, por ser um contact próprio que atende suas próprias demandas, sem outras unidades ou prestação de serviços terceirizados, que oscilam de acordo com a demanda 
econômica, proporciona ao estado uma maior estabilidade enquanto um ponto nodal na rede de teleatendimento brasileira.

Em suma, o Rio Grande do Norte se insere enquanto um ponto nodal na rede de teleatendimento brasileira devido às estratégias adotadas pelo setor para diminuir os fatores causadores de deseconomias de aglomeração, traduzidos em termos de aumento constante do custo de impostos e aluguéis, dificuldades de obtenção de espaço para a expansão, restrições legais, aumento de gastos e problemas com mão de obra, entre outros fatores. Processo viabilizado pela melhoria das redes infraestruturais e de serviços no território potiguar nas últimas décadas, aliado a ação governamental estadual em prol de atrair empresas de contact centers para o estado.

\section{CONSIDERAÇÕES FINAIS}

Os resultados obtidos nessa pesquisa demonstram que as políticas neoliberais tiveram um papel essencial para a gênese e expansão do setor de teleatendimento brasileiro, tendo em vista que a partir da privatização do setor de telecomunicações associada à abertura econômica ao capital estrangeiro, as detentoras do controle do sistema telefônico brasileiro criaram empresas especializadas em telesserviços conformando o setor de contact centers no país.

A partir da análise da divisão territorial do trabalho das empresas de contact centers, observamos a presença de forças centrípetas, com a manutenção das sedes e, assim, do poder, nas principais metrópoles brasileiras e, centrífugas, com a dispersão das unidades de produção para centros urbanos não metropolitanos, e para a região Nordeste. O que reforça o papel de comando da metrópole paulistana, que é potencializado pela centralização do capital, com a formação de grandes corporações através de fusões que passam a atuar como núcleos decisórios, aumentando a capacidade de emissão de ordens e informações para lugares cada vez mais distantes (ALMEIDA, 2013, p. 187).

Enquanto redes corporativas, a desconcentração das empresas de contact centers rumo a Região Nordeste é um processo planejado que visa diminuir os fatores causadores de deseconomias de aglomeração, e reflete a distribuição desigual das redes infraestruturais de transmissão de informações no território brasileiro, tendo em vista que a existência de redes materiais e imateriais (internet banda larga, telefonia, etc.) eficientes são imprescindíveis para a atividade de teleatendimento.

Dessa forma, a implantação de contact centers no Rio Grande do Norte decorre de um contexto de fluidez seletiva do território brasileiro, no qual as empresas dependem de um eficiente 
aparato tecnológico associado a normatizações favoráveis, visto que acordos políticos também definem as escalas de ação. Assim, a conformação da indústria de teleatendimento no território potiguar ocorre em primeira instância de uma necessidade econômica derivada da concorrência intrasetorial, com a exploração de vantagens locacionais advindas das especificidades locais da divisão socioterritorial do trabalho, com a consequente implantação de infraestruturas que permitiram conectar os lugares.

Do ponto de vista técnico, temos as políticas e programas de melhorias infraestruturais, como a universalização dos serviços de telecomunicações, e no âmbito normativo, as ações estatais com vista a flexibilização das leis trabalhistas, no que tange a terceirização e a normatização do telesserviço, a oferta de benefícios fiscais e territoriais e as parcerias firmadas visando a inserção da mão de obra local no setor de teleatendimento.

O Rio Grande do Norte representa nesse panorama uma localidade onde estas empresas podem se instalar e obter grandes lucros, sem o enfrentamento de grandes dificuldades, uma vez que o setor de teleatendimento é uma realidade ainda recente no estado, e não há mobilização sindical, nem representação de classe com relação à atividade profissional de teleatendimento, o que reflete os baixos salários e a precarização do trabalho como um todo, e se dá na dimensão das cidades que apresentam uma articulação/integração mínima com as redes técnicas nacionais.

Em suma, a implantação de empresas de teleatendimento no Rio Grande do Norte só foi possível devido a melhoria nas condicionantes técnicas, sociais e normativas pelas quais o estado vem passando nas últimas décadas. As redes infraestruturais, sobretudo, as infovias e a telemática, tem um peso importante para o estado ter se tornado um ponto nodal na rede de teleatendimento brasileira, e juntamente com a melhoria na qualificação da população, com a ampliação do ensino superior potiguar, representam os principais fatores de atratividade do estado.

O confronto entre os dados bibliográficos e documentais revelam que apesar do setor de teleatendimento potiguar ser resultante de uma lógica externa ao âmbito local, decorrente de estratégias territoriais de empresas que procuram dinamizar seus processos produtivos e melhorar sua competitividade, as empresas instaladas no território potiguar apresentam características próprias que se remetem as peculiaridades apresentadas pelos municípios nos quais se instalaram, e apontam para uma centralidade do município de Natal que apresenta o maior número de empresas do setor em seu território. 
O papel de centralidade exercido por Natal na conformação da indústria de teleatendimento potiguar se justifica de certo modo, mas não exclusivamente, pelo município ter sido uma das primeiras capitais estaduais do Nordeste a ser ocupada por empresas de teleatendimento do SulSudeste, sendo que enquanto capital regional, Natal apresenta uma alta concentração de atividades de gestão, despontando como ponto nodal do qual partem as demais redes infraestruturais e de serviços no território potiguar, o que viabiliza a sua integração à rede de teleatendimento brasileira.

\section{REFERÊNCIAS}

ALMEIDA, M. C. Em outro ponto da rede: desenvolvimento geográfico desigual e o "vaivém" do capital nas operações de contact center. 2013. Tese (Doutorado em Geografia) - Faculdade de Filosofia, Letras e Ciências Humanas, Universidade de São Paulo, São Paulo, 2013.

ANUÁRIO BRASILEIRO DE RELACIONAMENTO COM CLIENTES. O cenário dos contact centers no Brasil. São Paulo: Eireli, 2016.

CORRÊA, R. L. Dimensões de análise das redes geográficas. In: Trajetórias geográficas. Rio de Janeiro: Bertrand Brasil, 1997a, p. 279-318. 2012. . Redes geográficas: reflexões sobre um tema persistente. Rev. Cid., v.9, n. 16, p.199-128, Interações espaciais. In: CASTRO, I. E.; CORRÊA, R. L.; GOMES, P. C. C. (Org.). Explorações Geográficas. Rio de Janeiro: Bertrand Brasil, 1997, p. 279-318.

DIAS, L. C. Redes: emergência e organização. In: CASTRO, I. E.; CORRÊA, R. L.; GOMES, P. C. C. (Org.). Geografia: conceitos e temas. 2. ed. Rio de Janeiro: Bertrand Brasil, 2000, p. 141-162.

GUILLERME, A. L'émergence du concept de réseau 1820-1830. Groupe Réseaux, n. 5, p. 30-47, 1986. Disponível em: http://doi.org/10.3406/flux.1986.1085. Acesso em: 01 de julho de 2020.

INSTITUTO BRASILEIRO DE GEOGRAFIA E ESTATÍSTICA. Cadastro Central de Empresas. Atividade econômica de teleatendimento. IBGE. 2019.

MINISTÉRIO DO TRABALHO E EMPREGO. Relação Anual de Informações Sociais. Atividade de teleatendimento. RAIS, 2019.

OLIVEIRA, A. B. A importância do espaço geográfico na construção e funcionamento de redes científicas na área de farmácia em Pernambuco fomentadas pela Política Nacional de Ciência, Tecnologia e Inovação em Saúde (PNCTIS). 2014. Tese (doutorado em Geografia) - Universidade Federal de Pernambuco, Recife, 2014. 
PEREIRA, M. F. V. Redes, sistema de transportes e as novas dinâmicas do território no período atual: notas sobre o caso brasileiro. Rev. Soc. Nat., Uberlândia, v. 21, n. 1, p. 121-129, 2009. Disponível em: http://www.seer.ufu.br. Acesso em: 01 de julho de 2020.

PEREIRA, M. F. V.; KAHIL, S. P. O território e as redes: considerações a partir das estratégias de grandes empresas. In: GERARDI, L. H. O.; CARVALHO, P. F. (Org.). Geografia: ações e reflexões. Rio Claro: UNESP/IGCE: AGETEO, 2006, p. 219-229.

RAFFESTIN, C. Por uma Geografia do Poder. Rio de Janeiro: Ática, 1993.

SANTOS, M. A natureza do espaço. Técnica e tempo, razão e emoção. 3. ed. São Paulo: Hucitec, 1999.

SILVA, A. B. A emergência dos call centers na Região Metropolitana de Natal e suas repercussões no mercado de trabalho local. 2018. Monografia (Graduação em Geografia) Universidade Federal do Rio Grande do Norte, Natal/RN, 2018.

SILVEIRA, M. L. Globalización y território usado: imperativos y solidariedades. Cuadernos del CENDES, Caracas, v. 25, n. 69, p. 1-19, 2008. Disponível em: http://www.redalyc.org/service/redalyc/downloadPdf/403/403113920. Acesso em: 10 de março de 2018.

TOLEDO JÚNIOR, R. Telecomunicações e uso do território brasileiro. In: SOUZA, M. A. A. (Org.). Território brasileiro: Usos e abusos. Campinas: Territorial, 2003, p.93-105. 